Egyptian Journal of Aquatic Biology \& Fisheries

Zoology Department, Faculty of Science,

Ain Shams University, Cairo, Egypt.

ISSN $1110-6131$

Vol. 24(4): 249 - 266(2020)

www.ejabf.journals.ekb.eg

\title{
Reproductive traits and Microstructure of skeleton in both of Acropora digitifera and Acropora gemmifera (Scleractinia, Anthozoa) inhabiting the Northern Red Sea (Hurghada, Egypt)
}

\author{
Mohamed M. Rashad ${ }^{1 *}$, Walaa M. Shaban ${ }^{2}$, Abdel-Hamid A. M. Ali ${ }^{3}$, Hany A. Abdel-Salam ${ }^{1}$. \\ ${ }^{1}$ Zoology Department, Faculty of Science, Benha University, Benha 13518, Egypt \\ ${ }^{2}$ Zoology Department, Faculty of Science, Al-Azhar University, Nasr city 11651, Egypt. \\ ${ }^{3}$ National Institute of Oceanography and Fisheries (NIOF), Suez, Egypt. \\ *Corresponding Author:Mohamed.rashad79879@gmail.com
}

\section{ARTICLE INFO}

Article History:

Received: June 3, 2020

Accepted: June 19, 2020

Online: June 25, 2020

Keywords:

Scleractinian corals

Acropora

Micro-structure

Reproduction

Broadcasting Spawning

Red Sea

\section{ABSTRACT}

Reef-building scleractinian corals proliferate and maintain their populations, in part, through sexual reproduction. They typically reproduce sexually as either gonochoric (separate male and female) or hermaphroditic (producing both eggs and sperm) colonies. Both types of sexual reproduction achieved as spawning processes that take place once a year and this process affected by environmental conditions such as temperature, photoperiod and $\mathrm{pH}$ level. In relation, the current study was designed to explore the reproduction patterns of two Acroporoid coral species; Acropora digitifera and Acropora gemmifera, which inhabiting the northern Red Sea (Hurghada, Egypt). A scanning electron microscope (SEM) was used to identify both coral species and to obtain their microstructure details. For reproduction study purpose, gonads maturity status and spawning timing of both studied species were noticed, either by direct field observations, during the study period including two consecutive spawning seasons, or observed in aquaria, by taking live coral colony samples for watching their specific spawning release.

Results indicated that both investigated species are hermaphroditic broadcasting spawner (release buoyant egg-sperm bundles) and showed gradual gonads maturity development begin from October until their spawning time in late April. All polyps became empty from egg sperm bundles in early May. There was a clear relationship between the spawning time of the two coral species and the lunar cycle, temperature, and photoperiod. Spawning of study species occurred on nights (nearly 3-4 hours after sunset) during the new moon and full moon phases. The present study concluded that A. digitifera and A. gemmifera spawned before April full moon within two days.

\section{INTRODUCTION}

Coral reefs are reproductive species characteristic with a highly diversity which provide a shelter for an extraordinary biodiversity and support economics of many island and coastal communities (Connell, 1978 and Moberg \& Folke, 1999). Coral reef ecosystems are 
threatened by several factors; world widely, climate change, pollution and overexploitation (Hughes et al., 2003 and Lough, 2008). The existence of healthy reef and the recovery reef species are controlled by several environmental disturbance which dependent on gametes production, success fertilization, development of offspring, and survival of the new population (Richmond, 1997). All of these pathways are different and influenced by the interaction between coral biology and fluctuation in the environment (Tomascik \& Sander, 1987; Harrison \& Wallace, 1990; Richmond \& Hunter, 1990; Szmant \& Gassman, 1990; Hughes et al., 2000 and Baird et al., 2009).

There are two different primary modes of development in corals: broadcast spawning is the dominant way of sexual reproduction in reef building scleractinian corals (Harrison $\boldsymbol{\&}$ Wallace, 1990 and Baird et al., 2009). Broadcast spawner species can be gonochoric or hermaphroditic and release their gametes. About $65 \%$ of the scleractinian coral reef species are hermaphroditic broadcast spawners (Richmond \& Hunter, 1990; Guest $\boldsymbol{e t}$ al., 2008 and Baird et al., 2009a \& 2009b). Most of these species are released their gametes as a positively buoyant egg-sperm bundles (Arai et al., 1993 and Kinzie \& Buddemeier, 1996). Once the egg-sperm bundles have reached the sea surface, it's breaks within 10-35 minutes, where the external fertilization takes place. This in contrast to the brooder coral reef populations which can also be gonochoric or hermaphroditic, where the internal fertilization takes place inside the coral polyp and well-developed larvae are released (Harrison \& Wallace, 1990).

Reproduction of coral reef is controlled by different environmental factors as temperature, photoperiod and salinity that have been suggested to be cues to the corals to spawn simultaneously (Babcock et al., 1986; Oliver \& Babcock, 1992 and Bacocket al., 1994). However, many conflicting evidences are still unexplained. Corals in the Conzinct Island, Western Australia, as example experience about similar annual temperature and photoperiod cycles to those in the magnetic Island, Great Barrier Reef. However, they reproduce at six months different seasons (Simpson, 1985 and Babcock et al., 1986). Bachtiar (2001) demonstrated that corals growth take place in summer temperature for four months before they reproduce, spawn at the same time as corals grown in the ambient temperature, as well as corals grown in the shifted photoperiods.

The present study was aimed to determine the spawning season of two coral species in the Red Sea, Egypt. Also, this study provides some basic information on the reproductive cycle of broadcaster reef-building scleractinian corals in Red Sea water that are not available in a recent publication.

\section{MATERIALS AND METHODS}

\section{Study area:}

Stony corals are sensitive to environmental conditions and non-favorable conditions are likely to suppress their growth and reproduction, which in turn could lead to incorrect assumptions about their gametogenic development. So, after several prospections on different 
localities, we chose our two study area according to the health status of the coral reef community that have fewer pollutants. Two similar replicate sites were chosen in the Hurghada, Red Sea area including the coral reef habitat next to Remevyera resort shore (site, I) and Small Giftun Island shore (Site, II). In both selected sites, the two target species; Acropora digitifera and Acropora gemmifera occurred together with moderate coverage of coral reef patches (Fig. 1).

Site I: Remevyera resort (Co-ordinates: $27^{\circ} 09^{\prime} 99^{\prime \prime} \mathrm{N} \& 33^{\circ} 85^{\prime} 24^{\prime \prime}$ E). Remevyera resort, (13km South East to small Giftun Island, East to Hurghada Port) is a rocky site located east to Hurghada Port. This site surrounded with fringing reef with narrow reef flat. The reef slope extends almost vertically down to about $10 \mathrm{~m}$ depths followed by a sandy bottom with relatively abundant coral patches. Coral coverage on this island exceeds $40 \%$ and our studied species are well represented there.

Site II: Small Giftun Island (Co-ordinates: $27^{\circ} 11^{\prime} 09^{\prime N} \& 33^{\circ} 58^{\prime} 53^{\prime \prime}$ E). Small Giftun Island is a rocky island located east to Hurghada Port. The island surrounded with fringing reef with narrow reef flat. The reef slope extends almost vertically down to about $19 \mathrm{~m}$ depths followed by a sandy bottom with relatively abundant coral patches. Coral coverage on the island exceeds $60 \%$ and considered as high coverage site. This site faces high human impact in compare with the first site.

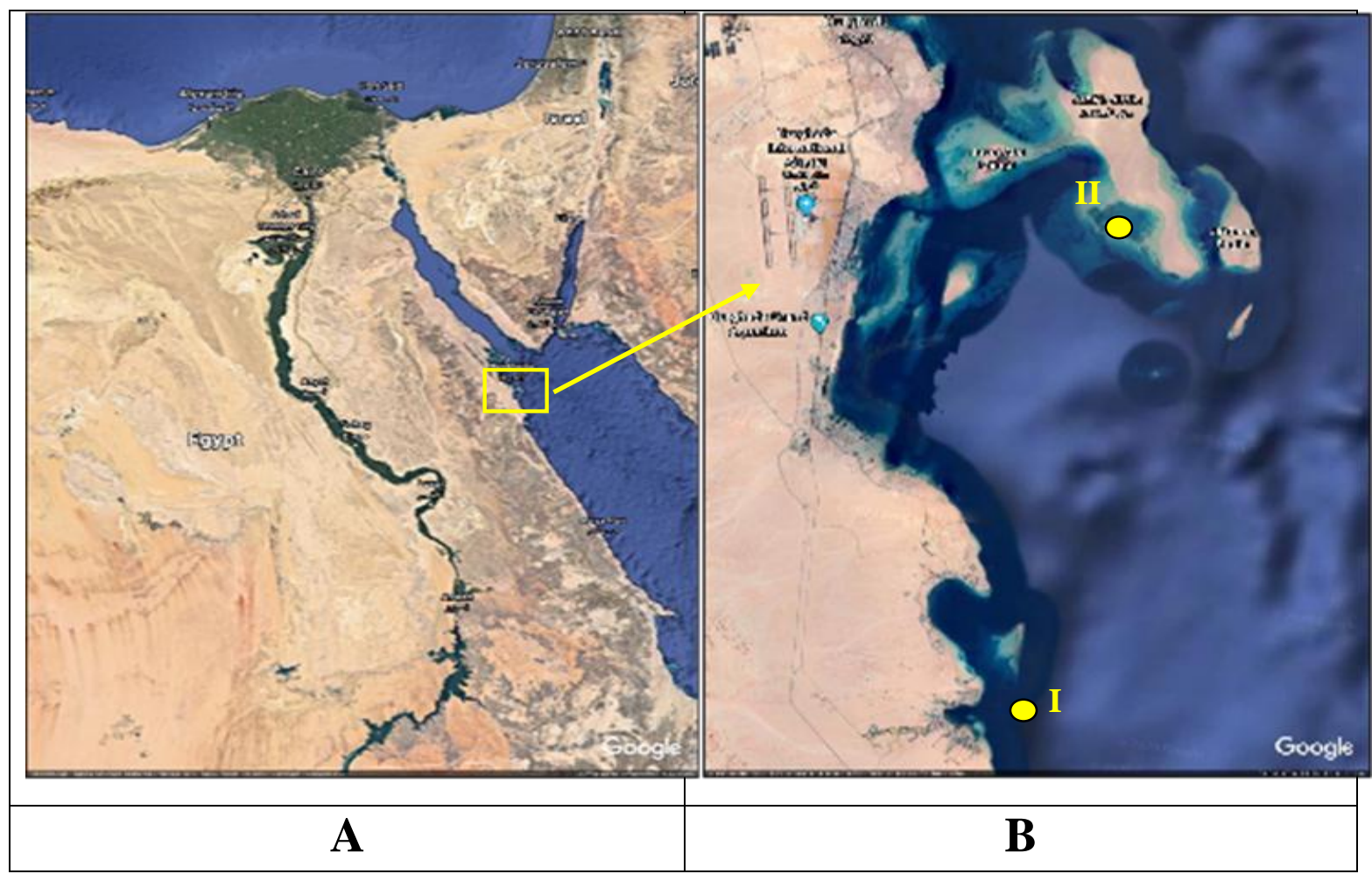

Fig. (1). (A) A map of the study area on Red Sea. (B) Enlarged subset of map A showing studying sites; site (I): Remevyera resort, site (II) Small Giftun Island. 


\section{Sampling and Identification of studied coral species:}

The two target species in this study from genus Acropora were identified firstly from the external shape, color and then we use the dissecting microscope to obtain features and ratio differences in the axial corallite, axial polyp and other taxonomical features according to Veron (2000) which used here as a guide for corals identification. Ten colonies from each species were chosen in both sites and tagged at the start date of the current study to investigate their spawning time and their mode of reproduction. The size of tagged A. digitifera and A. gemmifera colonies were chosen to be more than $30 \mathrm{~cm}$ in diameter but no much bigger, making sampling repetition is possible. Samples from different three branches ( $>5 \mathrm{~cm}$ length) were taken monthly from each tagged colony during the study period to see the coloration of the egg during maturation before releasing of gametes.

\section{Corals skeleton microstructure:}

For more accurate identification for target coral species A. digitifera and A. gemmifera used Scanning Electron Microscope (SEM) as a very effective tool in coral identification. So samples of both coral species polyps as well as hard skeleton were prepared for SEM investigation.

Polyp preparation: Specimens of live control and treatment corals were chopped off and immediately fixed in $4 \%$ formaldehyde $1 \%$ glutaraldehyde $(4 \mathrm{~F} 1 \mathrm{G})$, phosphate buffer solution $(\mathrm{pH} 7.2)$ at $4{ }^{\circ} \mathrm{C}$ for 3 hours. Polyp samples were washed in the buffer and dehydrated at $4{ }^{\circ} \mathrm{C}$ through a graded series of ethanol. These specimens were then post fixed in 2\% OSO4 in the same buffer at $4^{\circ} \mathrm{C}$ for 2 hours, then washed in the buffer solution, dehydrated at $4^{\circ} \mathrm{C}$ in a graded series of ethanol and dried by the critical point method.

Skeleton preparation: Colonies of A. digitifera and A. gemmifera were immersed in commercial bleach $(12 \% \mathrm{NaOCl})$ at $60{ }^{\circ} \mathrm{C}$ for $30 \mathrm{~min}$. After that the specimens washed in running tap water and rinsed several times in distilled water to remove the overlying soft tissues and other organic matter. The resultant whitened skeletons were then dried at room temperature until constant weight.

Microstructure investigation: The prepared samples and bleached skeletons were mounted using carbon paste on an Al-stub and coated with gold up to a thickness of $400 \AA$ in a sputter- coating unit (JFC-1100E). Investigations of the samples were performed in a JEOL JSM-5300 Scanning Electron Microscope (SEM) operated between 15 and $20 \mathrm{KeV}$ (kilo electron volt) according to Thomas (1962) and Tooze (1964).

\section{Environmental Measurements:}

The reproduction of corals and the maturation of its gonads affected by different environmental factors such as temperature, day-length, lunar cycle (before getting spawn). So, different environmental parameters were measured in the present study.

HANNA GPS Multiparameter Meter (HI 9829) was used to obtain monthly measurements of water temperature, $\mathrm{PH}$, Dissolved Oxygen, and salinity at the $4 \mathrm{~m}$ depth 
contour, which was in the middle of the depth zone where specimen collection was carried out at the study sites. The logging probe was lowered to $1 \mathrm{~m}$ of the bottom to avoid damage and blockage of the sensors due to sediment-suspension at the water-seabed interface.

Also, the day length (photoperiod from sunrise time to sunset time) was calculated in the sample day from the city calendar. Full moon status was determined in the day of the spawning of every selected colony of both studied species.

\section{Reproduction and spawning traits of $\boldsymbol{A}$. digitifera and $A$. gemmifera:}

Through regular field trips to both study sites, we checked the maturation of the oocytes, spawning timing, and modes of reproduction for different 10 separate colonies in every study site using SCUBA diving. Regular field observations with colonies sampling involved in the current study at least one time per month around the full moon date. In the months of spring season, we checked the colonies daily for each species from day five prior the full moon time and three days after.

To determine the maturation status, we had a monthly dive trip at the two study sites to see the target coral reef colonies and determined its oocyte maturation which carried out by recording the oocyte coloration through the period of the study.

As when colonies so close to spawning the mature egg-sperm bundles it's obvious on the corallite opening (calcia), the colonies release the egg-sperm bundles have a broadcasting mode of reproduction, while the colonies that release planula larvae they have broadening mode of reproduction.

\section{RESULTS}

\section{Morphological description of study species:}

The collected colonies of $A$. digitifera and A. gemmifera were solid, very porous, and branching. The individual coral animal is called the polyp (axial and radial). The skeleton deposited by an individual polyp within a colony is the corallite which composed of calcium carbonate. These colonies of $A$. digitifera (Dana, 1846)have two colors; brown color with purple branched tips and yellow color with creamy branched tips. As it have identical colony growth form (corymbose to digitate) with small terete branches. Branches are usually $1 \mathrm{~cm}$ in diameter; axial corallites are large, up to $4 \mathrm{~mm}$ wide. Radial corallites are about $1 \mathrm{~mm}$ in diameter, have thick lips on their lower side, and are aligned in rows. Colonies of $A$. gemmifera (Brook, 1892), are digitate. Branches are thick, tapering to small axial corallite. Radial corallites are of two sizes, usually in rows. The large sized corallites increase in length towards branch bases, where incipient axial corallites are common. A. gemmifera colonies are usually purple, blue, cream or brown, with blue or white branch tips. Generally axial corallites are larger than radial corallites and all the corallites of a colony are closely interconnected (Fig. 2). 


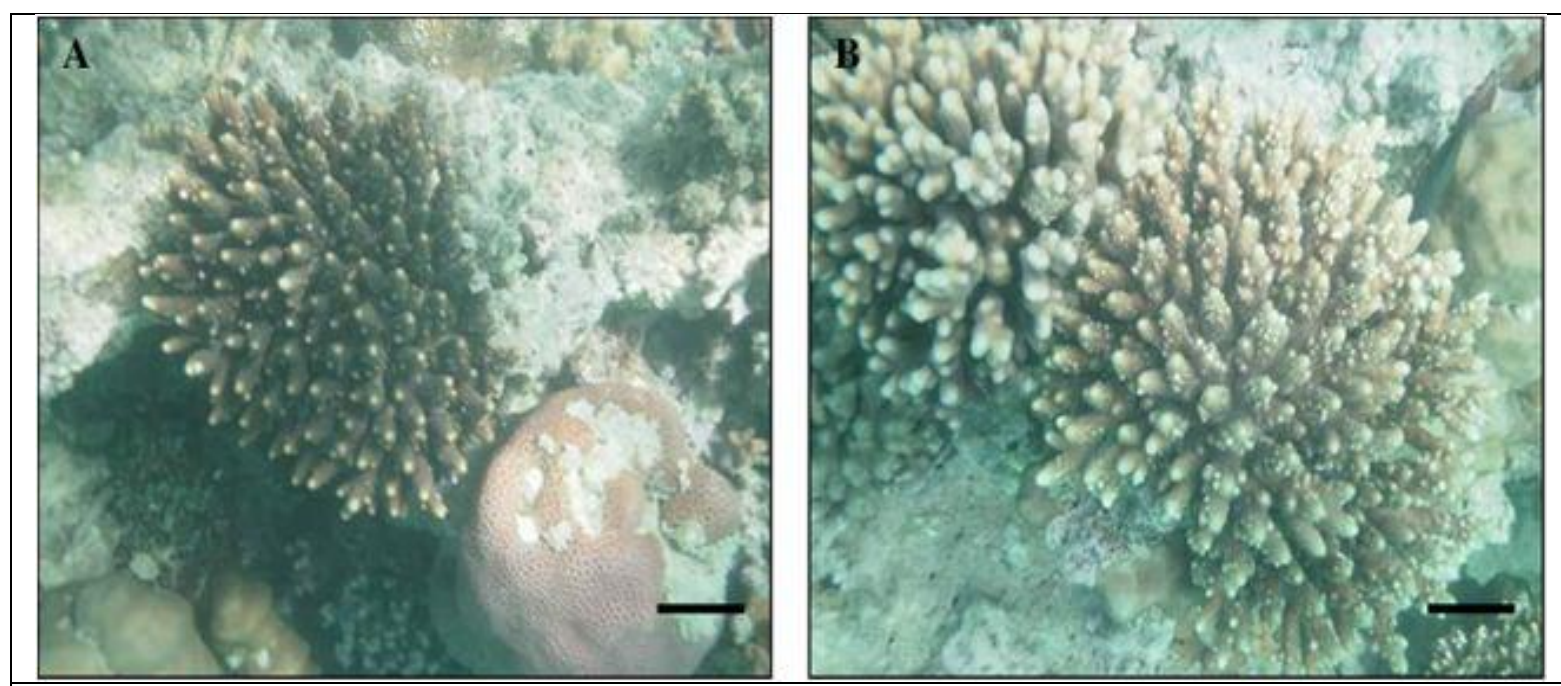

Fig. (2). Photographs of studied corals colonies; (A) A. digitifera and (B) A. gemmifera, scale bare $=1 \mathrm{~cm}$.

\section{Microstructure of $A$. digitifera and $A$. gemmifera:}

As shown in Figure 3 (A1, B1, B2), the individual branch of both A. digitifera and A. gemmifera respectively is formed of an axial polyp and many radial polyps. The axial and radial corallites are the skeletons of the polyps (Fig. 3 A1, A2, B1, B2). The corallite is defined by two regions, the calice and the theca. The upper oral surface of a corallite is the calice which opens to outside by a large opening known as calice opening or mouth opening which is large in $A$. digitifera (range from 0.96 to $1.5 \mathrm{~mm}$ in diameter), while that of $A$. gemmifera range from $(0,75$ to $1 \mathrm{~mm}$ in diameter). The calice opening is surrounded by a circle of sclerosepta arranged in two different level first six primary septa extend to the centre of the calcia and six secondary septa smaller than the primary ones. The theca is the wall of the corallite which consists of vertical rods arranged in concentric rings and horizontal radial and tangential bars. The radial bars form the sclerosepta along with the vertical units (the rods). The tangential bars are synapticulae that connect adjacent sclerosepta to one another (Fig. 3 A3, A4, B3, B4).

\section{Reproduction traits of $A$. digitifera and A. gemmifera:}

In situ examination of colonies, during which two studied coral Acropora species were sampled in both years (2018 and 2019), showed that both of the two species in 2018 and 2019 clearly synchronized. Oocytes maturation was recorded in A. gemmifera and A. digitifera, where both followed the same color regime during the maturation process with no significant difference in gonad coloration trend, in which oogenesis was accompanied by color change in developing oocytes. It colored white or pale white in immature stages, and changed during the maturation stages from light cream to pink just before spawning (Table 1 and Figs. 4 \& 5). Such gonad data were quite evident that our studied species are hermaphrodites, contained oocytes and spermaries in the same polyp but in different mesenteries. 


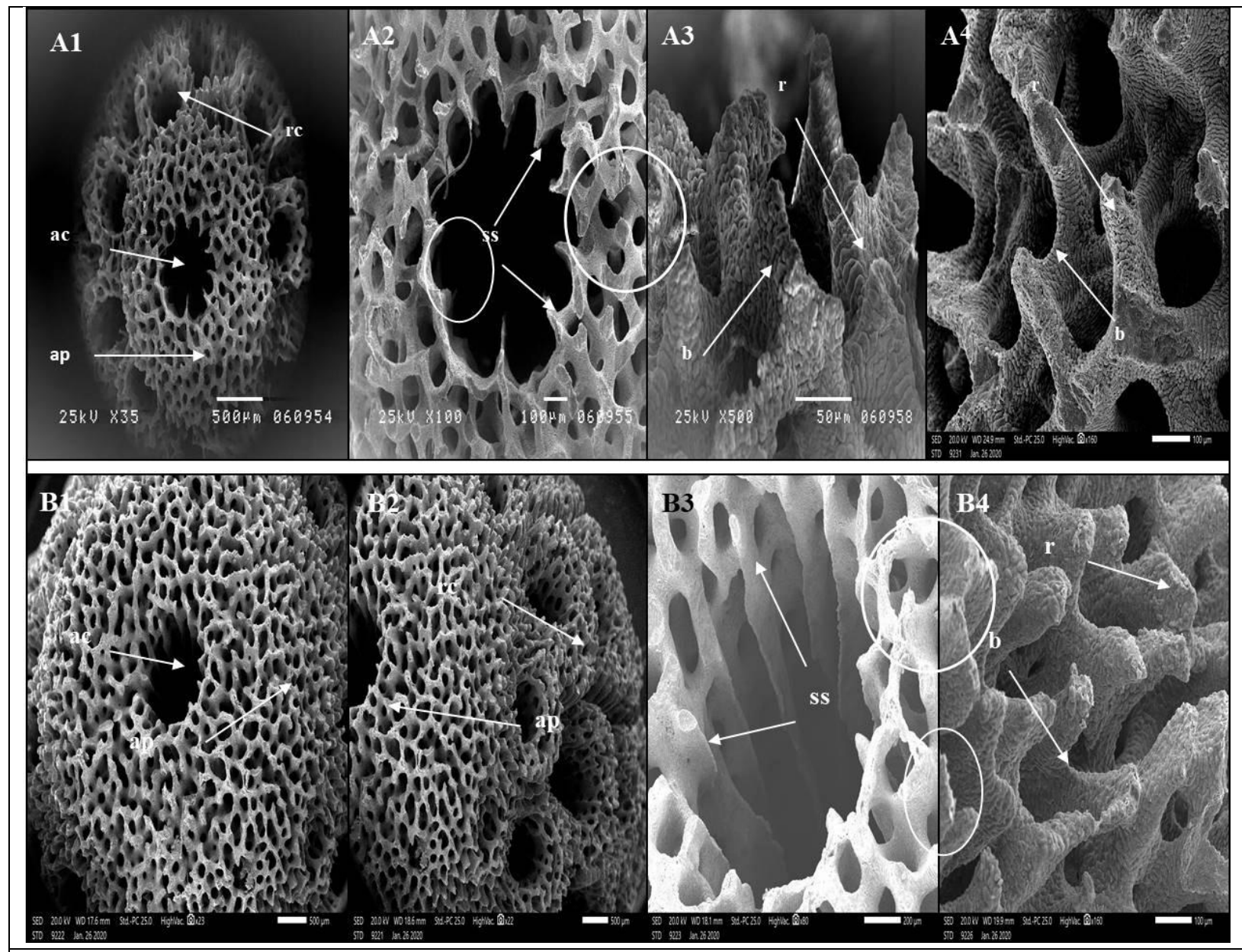

Fig. (3). Scanning electron micrographs of A. digitifera (A) and A. gemmifera (B). (A1) upper view for both axial and radial skeleton branches; (A2) upper view of the axial corallite showing rods and bars (circle); (A3,A4) rods and bars of axial corallite; (B1) upper view for individual branch showing axial corallite and axial polyp; (B2) lateral view of branch show the radial corallite and radial polyp; (B3) upper view for axial corallite with its sclerosepta showing rods and bars (circle); (B4) rods and bars of axial polyp. Abbreviations: ac, axial corallite; ap, axial polyp; rc, radial corallite; rp, rdaial polyp; ss, sclerosepta; r, rods;

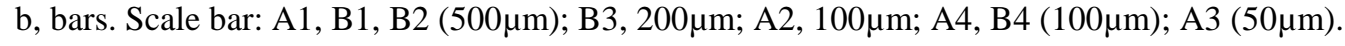

Table (1) shows the common coloration trend of oocytes in both synchronized spawner species under investigation. This color trend was recorded as a result of daily observation during the active gametogenesis process and during the mass spawning event period. The time of the maximum occurrence of each of the oocytes color ranked as days prior to spawning event and indicated that the active gametogenesis process commonly occurred within a month before spawning. The vitallogenesis process took less than 4 weeks where gonad color changed from light cream to cream to pink. It seemed that the rhythm of changes in oocytes coloration between different studied species occurred between cream to light pink coloration (vitallogenesis stage), while mostly all of the studied species reached to ripe or fully mature oocytes (Pink color) at the same time at maximum 4 days before spawning (Figs. 4\&5). 
Table (1). Oocytes coloration during the different stages of maturation of both studied Acropora species.

\begin{tabular}{|c|c|c|c|c|c|}
\hline Oocytes Status & Immature & Premature Stage I & Premature Stage II & Premature Stage III & Mature \\
\hline Oocytes colour & White & Light Cream & Cream & Light pink & Pink \\
\hline
\end{tabular}

Fertile colonies are found in the population of A. digitifera and A. gemmifera from collected samples in (March, April 2018 and February, March 2019) at both study sites (Tables $2 \&$ 3). Consequently, after spawning time, and for three months later spawning, gonads are empty or not big enough to be obvious and it is not observed. From October to January there is a reduction in the proportion of fertile colonies which gradually increase, return to be mature and the reproductive synchrony is relatively take place between both current studied species with fertile colonies over $90 \%$ in March before full moon month (April) with $100 \%$ maturity percentage (Figs. 6 \& 7).

The surface sea water temperature increases gradually with monthly means range from 22.30 to $24,89^{\circ} \mathrm{C}$ between March 2018 and May 2018, and in the same period there's increase of photoperiod (day length) and no clear significant in the PH level as shown in (Table 4). Sea water temperature increase during October 2018 leads to develop in the gonads maturation. Consequently, the current study showed that eggs in A. digitifera develop very slowly from July to September 2018, and then they develop very rapidly from October 2018 to March 2019 (Fig. 6). While, eggs in A. gemmifera develop very slowly from July to October 2018, then they develop very rapidly from November 2018 to March 2019 (Fig., 7). All colonies spawn one time a year in April full moon. However, some colonies were also found to have ripe oocytes before full moon of January 2019 suggesting that some colonies in the population may have spawning before the spawning peak in April 2019 for both study species. On the other hand, testes of both A. digitifera and A. gemmifera develop after the full moon of November 2018. Before the full moon of April 2018 and March 2019 most of colonies contained ripe testes (Tables $2 \& \mathbf{3}$ ). These results suggested that most colonies in this population ready to spawn prior to the full moon of April 2018.

Regarding to spawning synchronization of corals in the two different study sites, results in Tables (3\&4) indicated that A. digitifera and A. gemmifera at both study sites show high degrees of synchrony on their reproductive cycles whereas the peak of spawning season of this coral is likely before the full moon of April. At all, colonies of A. digitifera and A. gemmifera spawn between the first and second day before April full moon. It was found that in the $28^{\text {th }}$ of April 2018 (two days before the full moon), fresh broken colonies in the both study sites contained pinkish eggs (Table, 5). The following day (just before the full moon), pinkish eggs were found in some colonies at both study sites which indicate that the spawning extend to the full moon time. The ripe colonies were tagged at this time. In the next day after the April full moon, there were no longer eggs in the tagged colonies suggesting that the spawning had taken place. 
Table (2). Monthly field observation detection of oocytes and spermaries occurrence in Acropora digitifera colonies at two different studied sites.

\begin{tabular}{|l|c|c|c|c|c|c|}
\hline \multirow{2}{*}{ Months } & \multicolumn{4}{|c|}{ Site (I) } & \multicolumn{3}{c|}{ Site (II) } \\
\cline { 2 - 7 } & Cl-Ooc. & Cl-Sp. & Ooc. Color & Cl-Ooc. & Cl-Sp. & Ooc. color \\
\hline Mar-18 & $\mathbf{1 0}$ & $\mathbf{1 0}$ & pale cream to light pink & $\mathbf{1 0}$ & $\mathbf{1 0}$ & pale cream to light pink \\
\hline Apr-18 & $\mathbf{1 0}$ & $\mathbf{1 0}$ & light pink to pink & $\mathbf{1 0}$ & $\mathbf{1 0}$ & light pink to pink \\
\hline May-18 & $\mathbf{0}$ & $\mathbf{0}$ & Empty & $\mathbf{0}$ & $\mathbf{0}$ & Empty \\
\hline June-18 & $\mathbf{0}$ & $\mathbf{0}$ & Empty & $\mathbf{0}$ & $\mathbf{0}$ & Empty \\
\hline July-18: Sep-18 & $\mathbf{N S}$ & $\mathbf{N S}$ & NS & NS & NS & NS \\
\hline Oct-18 & $\mathbf{6}$ & $\mathbf{0}$ & light white & $\mathbf{6}$ & $\mathbf{0}$ & light white \\
\hline Nov-18 & $\mathbf{8}$ & $\mathbf{1}$ & light white & $\mathbf{7}$ & $\mathbf{1}$ & light white \\
\hline Dec-18 & $\mathbf{8}$ & $\mathbf{4}$ & light white & $\mathbf{8}$ & $\mathbf{4}$ & light white \\
\hline Jan-19 & $\mathbf{9}$ & $\mathbf{6}$ & light white to white & $\mathbf{9}$ & $\mathbf{5}$ & light white to white \\
\hline Feb-19 & $\mathbf{1 0}$ & $\mathbf{7}$ & white to pale cream & $\mathbf{1 0}$ & $\mathbf{7}$ & white to pale cream \\
\hline Mar-19 & $\mathbf{1 0}$ & $\mathbf{1 0}$ & pale cream to cram & $\mathbf{1 0}$ & $\mathbf{1 0}$ & pale cream to cream \\
\hline
\end{tabular}

Cl-Ooc.: number of colonies observed have oocytes; Cl-Sp.: number of colonies observed have sperms;

Ooc. Color: oocytes color that observed after cross section is taken in the colony; NS: not observed.

Table (3). Monthly field observation detection of oocytes and spermaries occurrence in Acropora gemmifera colonies at two different studied sites.

\begin{tabular}{|l|c|c|l|c|c|l|}
\hline \multirow{2}{*}{ Months } & \multicolumn{4}{|c|}{ Site (I) } & \multicolumn{3}{c|}{ Site (II) } \\
\cline { 2 - 7 } & Cl-Ooc. & Cl-Sp. & \multicolumn{1}{c|}{ Ooc. Color } & Cl-Ooc. & Cl-Sp. & \multicolumn{1}{c|}{ Ooc. color } \\
\hline Mar-18 & 10 & 10 & Pale cream to cream & 10 & 10 & Pale cream to cream \\
\hline Apr-18 & 10 & 10 & Cream to pink & 10 & 10 & Cream to pink \\
\hline May-18 & 0 & 0 & Empty & 0 & 0 & empty \\
\hline June-18 & 0 & 0 & Empty & 0 & 0 & empty \\
\hline July-18: Sep-18 & NS & NS & NS & NS & NS & NS \\
\hline Oct-18 & 5 & 0 & light white & 5 & 0 & light white \\
\hline Nov-18 & 6 & 1 & light white & 5 & 1 & light white \\
\hline Dec-18 & 7 & 2 & light white & 7 & 2 & light white \\
\hline Jan-19 & 9 & 5 & light white to white & 8 & 5 & light white to white \\
\hline Feb-19 & 10 & 7 & white to pale cream & 10 & 6 & white to pale cream \\
\hline Mar-19 & 10 & 10 & pale cream to cram & 10 & 10 & pale cream to cream \\
\hline
\end{tabular}

Cl-Ooc.: number of colonies observed have an oocytes; Cl-Sp.: number of colonies observed have an sperms; Ooc. Color: oocytes color that observed after cross section is taken in the colony; NS: not observed. 




Fig. (4). Photograph showed the branch of Acropora digitifera with mesentries containing oocyte (A), and soft tissue after decalcification show the mesentries which contain both of oocyte and spermaries (B). Mes: Mesentries; Sp: Sperms; Ooc: Oocyte (Scale bar $=500 \mu m)$

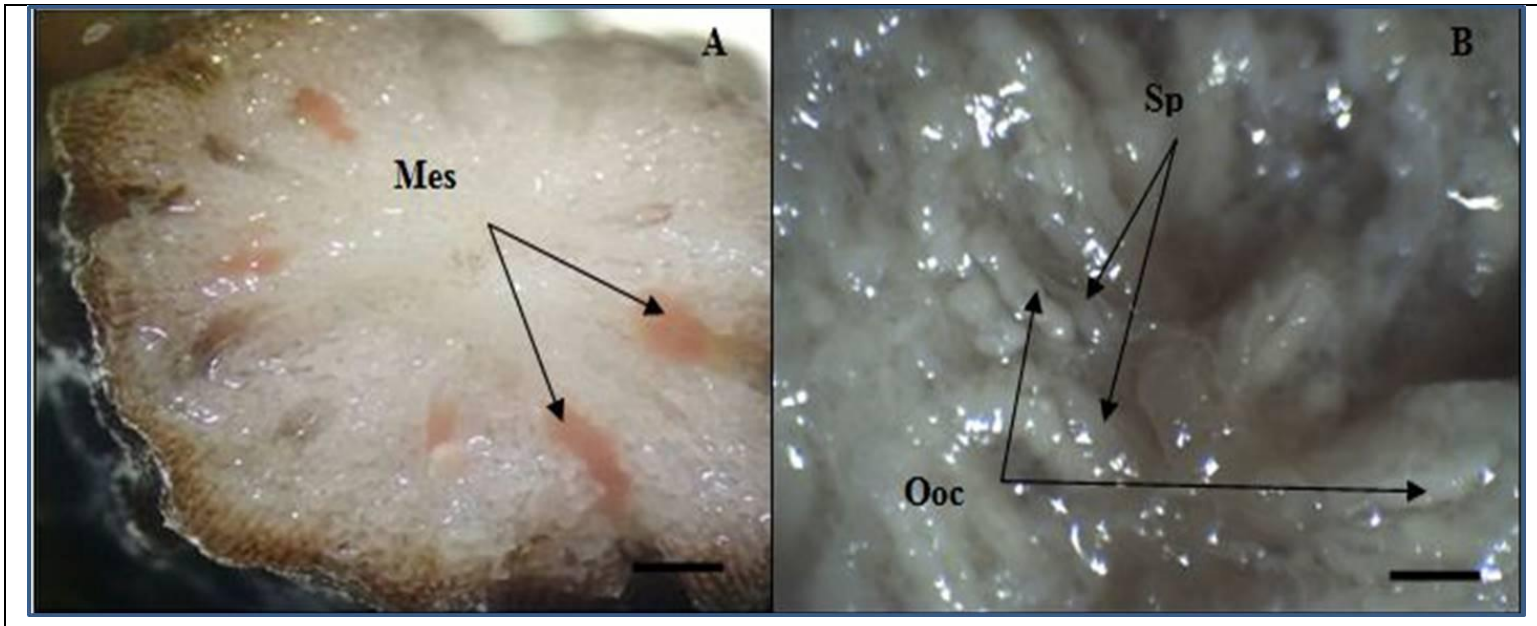

Fig. (5): Photograph showed the branch of Acropora gemmifera with mesentries containing oocyte (A), and soft tissue after decalcification show the mesentries which contain both of oocyte and spermaries (B). Mes: Mesentries; Sp: Spermaries; Ooc: Oocyte (Scale bar $=500 \mu \mathrm{m})$

Table 4. Monthly average values of day light and water parameters in the study area.

\begin{tabular}{|l|l|l|l|l|l|}
\hline Months & \multicolumn{1}{|c|}{$\mathbf{T}\left({ }^{\circ} \mathbf{C}\right)$} & \multicolumn{1}{|c|}{ Day L (h) } & \multicolumn{1}{|c|}{ Salinity (\%o) } & \multicolumn{1}{c|}{$\mathbf{p H}$} & \multicolumn{1}{c|}{$\mathbf{D O}$ (mg/L) } \\
\hline Mar-18 & $22.30 \pm 0.15$ & $12.01 \pm 0.25$ & $40.2 \pm 0.01$ & $8.072 \pm 0.009$ & $7.175 \pm 0.019$ \\
\hline Apr-18 & $22.8 \pm 0.45$ & $12.82 \pm 0.22$ & $40.25 \pm 0.014$ & $7.76 \pm 0.010$ & $7.135 \pm 0.033$ \\
\hline May-18 & $24.89 \pm 0.79$ & $13.49 \pm 0.17$ & $40.245 \pm 0.01$ & $8.073 \pm 0.0084$ & $7.097 \pm 0.013$ \\
\hline June-18 & $26.67 \pm 0.39$ & $13.82 \pm 0.05$ & $41.26 \pm 0.093$ & $8.208 \pm 0.016$ & $6.82 \pm 0.094$ \\
\hline Oct-18 & $27.21 \pm 0.137$ & $11.29 \pm 0.08$ & $40.218 \pm 0.019$ & $8.21 \pm 0.01$ & $6.53 \pm 0.018$ \\
\hline Nov-18 & $26.23 \pm 0.133$ & $10.66 \pm 0.005$ & $40.091 \pm 0.083$ & $8.21 \pm 0.01$ & $6.948 \pm 0.0155$ \\
\hline Dec-18 & $21.94 \pm 0.242$ & $10.42 \pm 0.005$ & $40.445 \pm 0.031$ & $8.11 \pm 0.013$ & $7.256 \pm 0.020$ \\
\hline Jan-19 & $22.45 \pm 0.217$ & $10.72 \pm 0.055$ & $40.446 \pm 0.02$ & $7.977 \pm 0.008$ & $7.194 \pm 0.015$ \\
\hline Feb-19 & $22.15 \pm 0.184$ & $11.36 \pm 0.08$ & $40.467 \pm 0.015$ & $8.101 \pm 0.012$ & $7.22 \pm 0.027$ \\
\hline Mar-19 & $22.71 \pm 0.137$ & $12.16 \pm 0.08$ & $40.321 \pm 0.0285$ & $8.08 \pm 0.007$ & $7.177 \pm 0.012$ \\
\hline
\end{tabular}


Table 5. Spawning timing of studied coral species.

\begin{tabular}{|l|c|c|c|}
\hline Acropora spp. & Spawning slicks observed & Full moon date & Nights before (-) or after (+) full moon \\
\hline A. digitifera & 28 April 2018 & 30 April 2018 & $\mathbf{- 2}$ \\
\cline { 1 - 1 } A. gemmifera & 28 April 2018 & & $\mathbf{- 2}$ \\
\hline
\end{tabular}

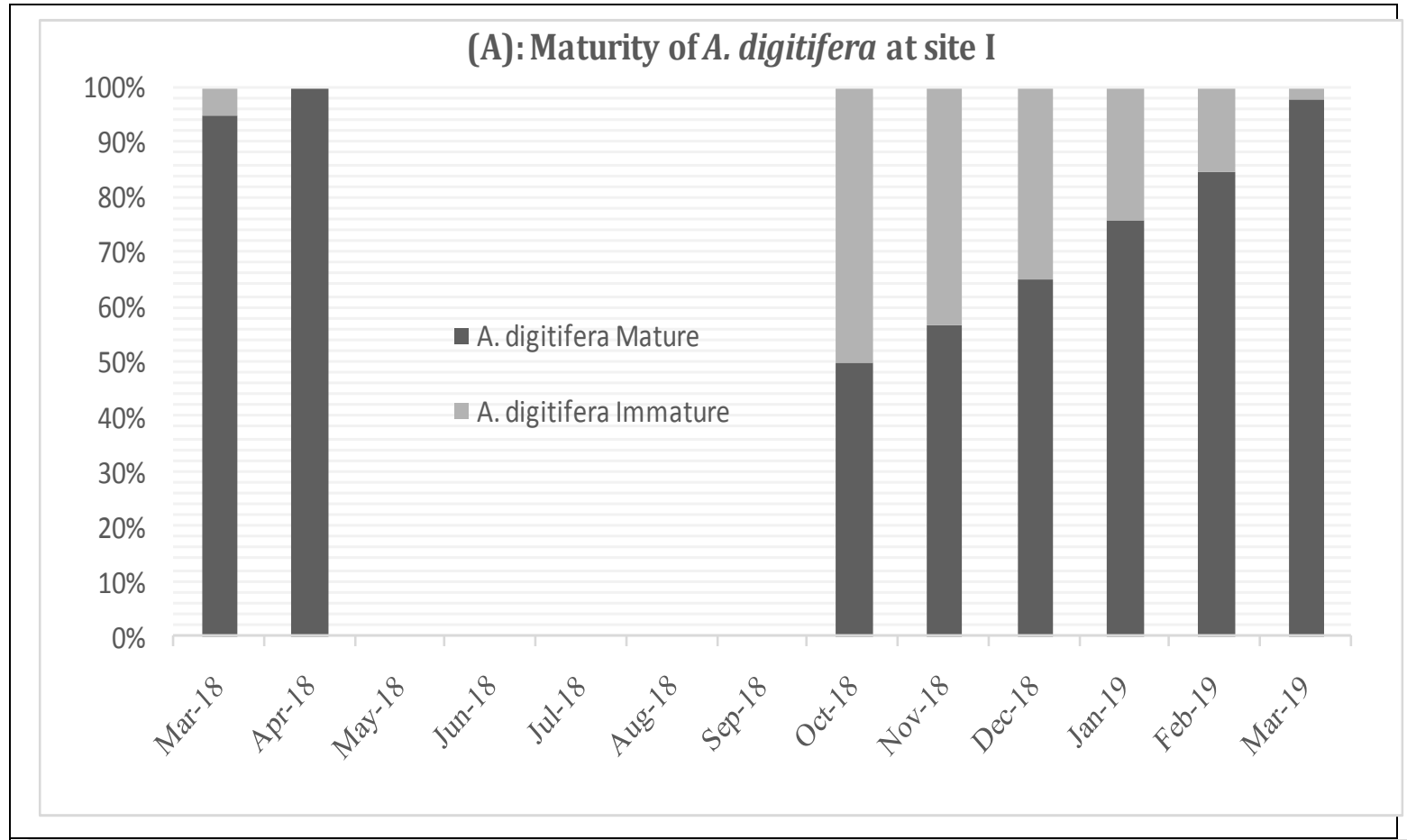

(B): Maturity of $A$, digitifera at site II

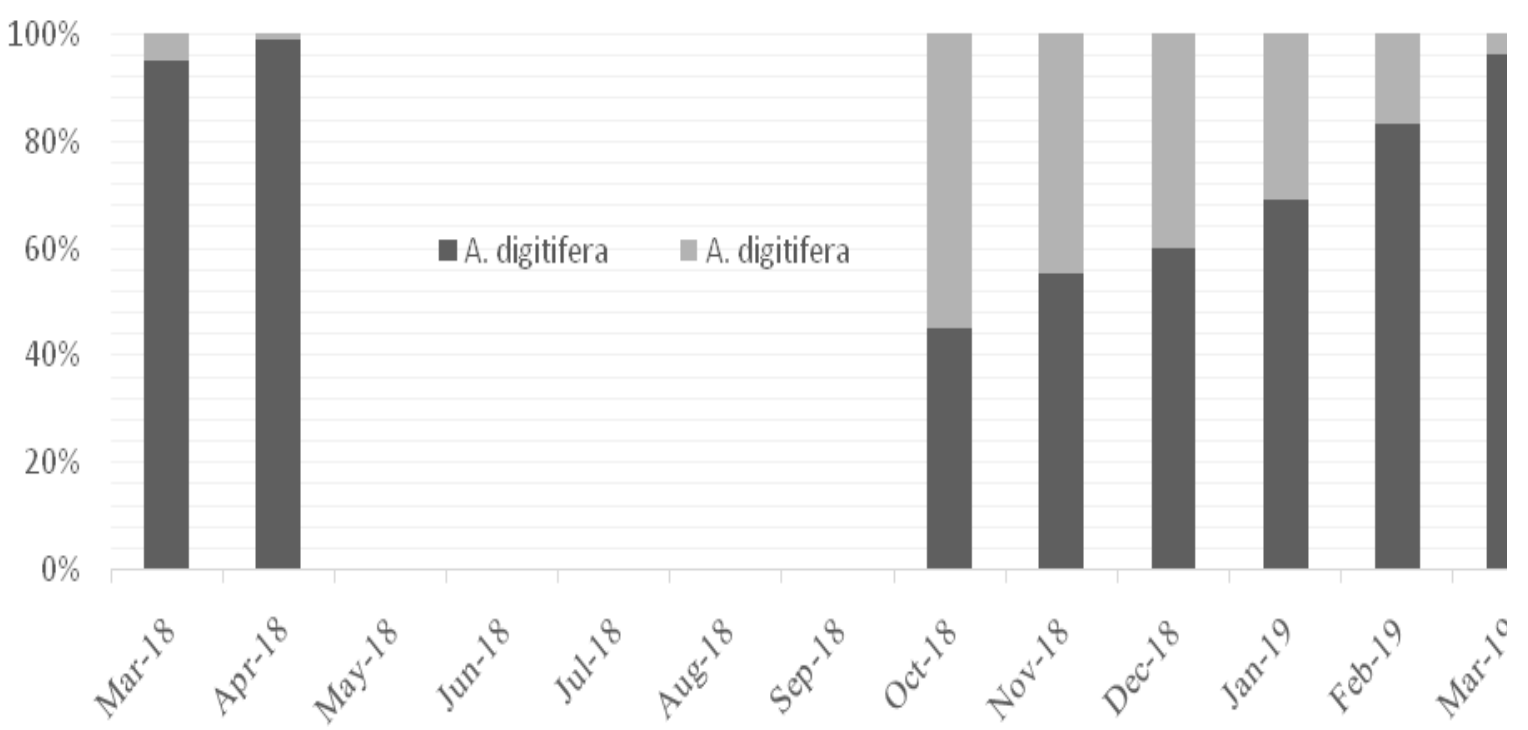

Fig. (6). Monthly immature and mature colonies percentages (\%) of A. digitifera at site I (A) and site II (B) during study period. 


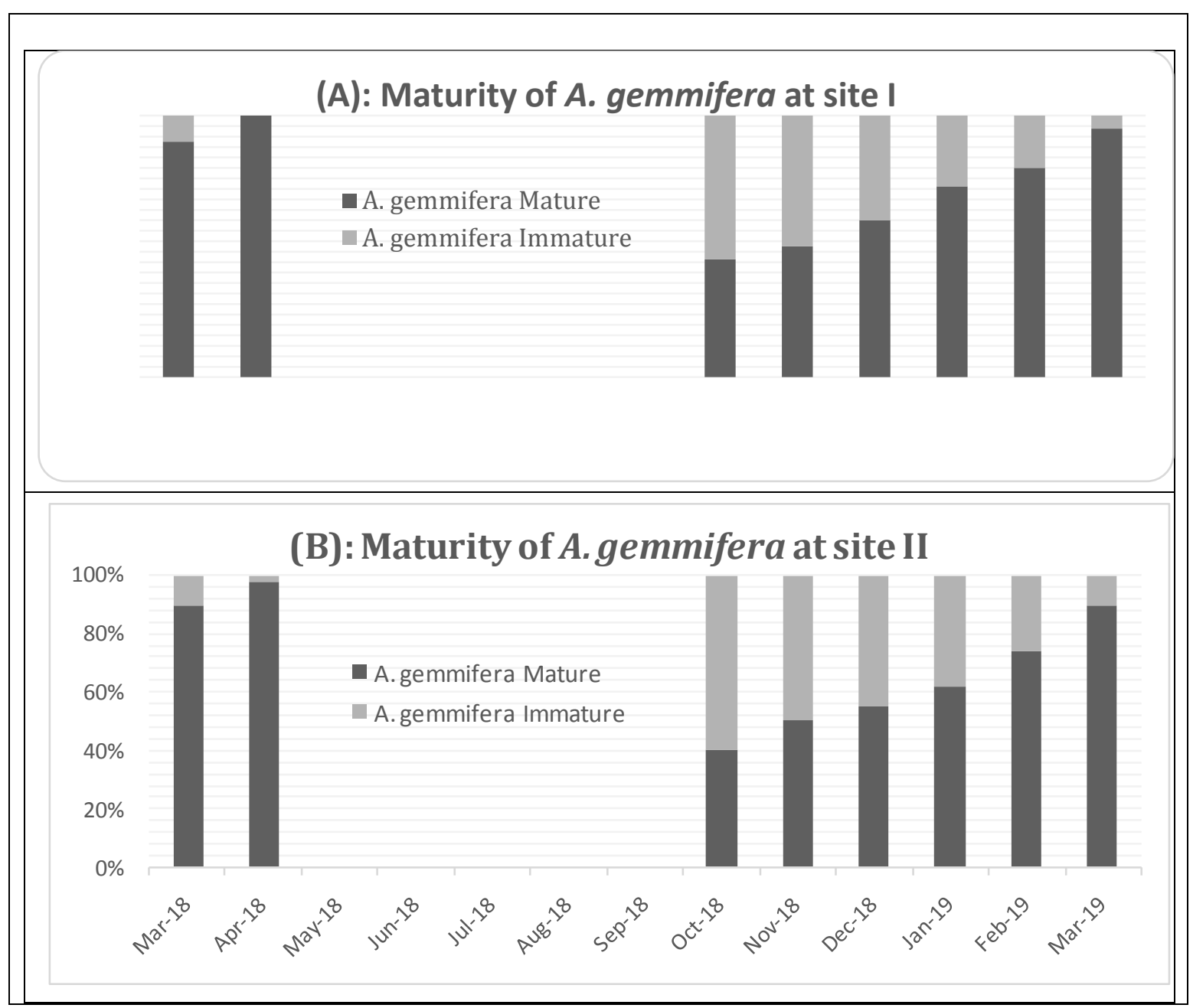

Fig. 7.Monthly immature and mature colonies percentages (\%) of A. gemmifera at site I (A) and site II (B) during study period.

\section{DISCUSSION}

Genus Acropora is one of the widest spared genera around the world comprises 182 species recorded in different reefs around the world with about 42 species recorded in the Red Sea (Wallace, 1999 and Veron, 2000). Acropora spp. are hermaphroditic, which produce both male and female gametes in the polyps of the colonies, and there is no evidence that members of this genus had a gametes maturation spike but had a single annual gametogenic cycle (Wallace, 1985; Szmant, 1986; Mangubhai \& Harrison, 2008a \& 2008b; Rosser \& Gilmour, 2008). Among present observations in the Hurghada waters in Red Sea, it was cleared that Acropora digitifera and Acropora gemmifera are not exception and the present study ensured that both species are hermaphroditic broadcasting spawners in which process it observed release their buoyant egg-sperm bundles. 
In the present work, Synchrony in gamete maturation of two corals, A. digitifera and A. gemmifera, assemblages at these Red Sea sites is among the highest ever recorded. The proportion of mature colonies in this season at these sites $(99 \%$ of colonies mature at both study sites Hurghada in April 2018) is higher than for Acropora on the Great Barrier Reef, where, for example, values for the proportion of colonies with mature oocytes in the weeks preceding the mass spawning period (Willis et al., 1985) in 1999 were $72 \%$ in the central Great Barrier Reef and 63\% in the northern Great Barrier Reef (Baird \& Marshall, 2002). Similarly, the proportion of Acropora colonies breeding in a typical Western Australian mass spawning period was 66\% depending on direct observation by (Babcock et al., 1986). In the same way, the proportion of Acropora species breeding is similar to that on these Australian reefs by (Penland et al., 2004), (86\% in the central Great Barrier Reef, 65\% in the northern Great Barrier Reef and 95\% in Western Australian).

In the present study, both $A$. digitifera and A. gemmifera are likely to have only one gametogenic cycle per year as their colonies spawned before March full moon 2018. Bachtiar (2001) suggested that low synchrony in the spawning of the corals A. nobilis, A. cytherea and Hydnophora rigida in the Gili Trawangan and Gili Meno, Indonesia is likely owing to the low variation on environmental factors (Temperature, Photoperiod) that may constrain and limits the stages of reproductive cycles. In the Red Sea water temperature is nearly always warm at most of the time. Because broadcasting corals require external fertilization, responding similarly to specific environmental signals to ensure conspecific reproductive synchrony (in the order of minutes, e.g. Levitan et al.. (2004) is probably of prime importance to ensure high fertilization rates. Thus, one of the most possible hypotheses explaining multi-species spawning is that species respond similarly but independently to timing cues to synchronize spawning within populations (Bachtiar, 2001), resulting in many species having short overlapping spawning periods. No coastal location is truly seasonal, even equatorial reefs experience marked rhythmic changes in sea surface temperature. Consequently, mass spawning is just as likely to occur on the Red Sea reefs as it is at higher latitudes; indeed, this remarkable phenomenon is probably a feature of all species coral assemblages.

There's no indication here for the biannual gametogenic cycle for both coral species. The biannual gametogenic cycle has been reported to takes place in the corals Montipora digitata, Montipora aequituberculata, and Montipora platiformisin the Great Barrier Reef (Wijayantiet al., 2019). Multiannual gametogenic cycle has also been found in the $A$. pallifera species in Papua New Guinea (Randall et al., 2020). In the A. pallifera gametogenic process takes place continuously and overlapping each other. The biannual gametogenic cycle may give benefit to the coral increase reproductive output, particularly for corals with low local population density.

The spawning season within population of the two studied corals is restricted during the particularly full moon in the middle of the spring season over only one month. Most corals close to equatorial may have spawning season spread over several months, as in Palau, for example, in which spawning of 13 corals spread over more than three months (Kenyon, 
1995). Corals which have narrow spawning time (in mass spawning event) in the Great Barrier Reef, they spawn in several months when they live in equatorial region of Papua New Guinea (Oliver et al., 1988). The same phenomenon is not likely to occur in the two corals, although the present study hasn't revealed clearly the length of the spread spawning season. The spread of the spawning season has been thought to have some disadvantages to the coral reproductive success, to oppose the synchronous spawning. The spread of the spawning season may reduce the chance of the sperm to fertilize the eggs and may reduce survivorship of planula larvae from predatory (Oliver \& Babcock, 1988).

Many previous studies interested by coral spawning prediction( based on available evidence) indicated that reproductive conditions can be estimated based on the visibility and color of developing oocytes (Baird \& Marshall, 2002). Visible pigmented oocytes are mature and most likely will be released around the next full moon (Willis et al., 1985; Babcock $\boldsymbol{e t}$ al., 1986 and Oliver et al., 1988). Visible white oocytes are close to maturity and are likely to be spawned within 1-3 months. Colonies in which oocytes are not visible either have recently spawned or are unlikely to do so for at least 3 months (Harrison et al., 1984; Baird \& Marshall, 2002 and Guest et al., 2005a \& 2005b). None of these previous studies concerned the detailed changes in color of oocytes during the active gametogenesis of the corals. The present study gives a detailed investigation on the using of oocytes colorations for the examination and prediction of spawning time of Acropora spp. in the Red Sea. The oocytes colors were white and light cream during immature and early premature stages (more than 4 weeks) prior to the spawning time. At the vitellogenesis stage the color changes from light cream to cream to light pink and reach the pink color at the fully mature stage few days prior to spawning days.

All the previous studies which used the same method of oocytes color to predict the time of coral spawning did not record the phenomena of oocytes coloration at the field and mentioned only the pigmentation of oocytes prior to spawning time. However, Babcock $\boldsymbol{e t}$ al., (1986), studied the spawning of 105 scleractinian coral species on the Great Barrier Reef, and found that the oocytes color of A. cythera, A. formosa, A. gemmifera, A. humilis, A. selago, and $A$. tenuis at the spawning time were pink which agree with this study, and the oocytes color of the most of the others Acropora spp. were pink or red (Babcock et al., 1986) which are in coincidence with the present findings that, the color scheme which stated in this study can be used in other places around the world.

In the Red Sea temperature and solar irradiance remain within ranges that are suitable for spawning of corals to occur elsewhere (e.g., Hayashibara et al., 1993; Babcock et al., 1994 and Penland et al., 2004). In other words, conditions are suitable for breeding all year round, so it seems unlikely that the timing of reproduction in any scleractinian is limited to certain times of the year by resource availability. It is not clear whether there is an adaptive (ultimate) advantage to spawning when environmental conditions are likely to be "optimal" for fertilization, larval development, survival and settlement. As the environmental condition 
reach the suitable level for spawning, mean temperature was $22.8 \pm 0.45{ }^{\circ} \mathrm{C}$ and photoperiod was $12.82 \pm 0.22 \mathrm{hr}$ that was optimal condition for spawning of two study species.

The knowledge of spawning times in coral can be a good indicator for reproduction in other groups. Also, knowing the timing and synchrony of coral spawning can help in explaining the success or failure in annual coral replenishment due to corresponding climatic conditions (Mendes \& Woodley, 2002). Knowing the time of reproductive events can also allow for more effective management of pulse impacts from coastal development on coral reef ecosystems (Richmond, 1997). Based on the results of the present study we concluded that the spawning peak of the two study species take place before April 2018 full moon with two days, as the gonads reached their maturation in optimal environmental condition for both $A$. digitifera and $A$. gemmifera in this time. The seasonal nature of coral spawning around the globe affords environmental managers the opportunity to place temporal restrictions on human impacts that undermine the early development of coral larvae (Guest et al., 2005b).

\section{REFERENCES}

Arai, T.; Kato M.; Heyward, A.; Ikeda, Y.; Iizuka, T. and Maruyama, T. (1993). Lipid composition of positively buoyant eggs of reef building corals. Coral Reefs, 12 (2), 71 75.

Babcock, R. C.; Bull, G. D.; Harrison, P. L.; Heyward, A. J.; Oliver, J. K.; Wallace, C. C. and Willis, B. L. (1986). Synchronous spawning of 105 scleractinian coral species on the Great Barrier Reef. Marine Biology, 90 (3), 379-394.

Babcock, R. C.; Willis, B. L. and Simpson, C. J. (1994). Mass spawning of corals on a high latitude coral reef. Coral Reefs, 13 (3): 161-169.

Bachtiar, I. (2001). Reproduction of three scleractinian corals (Acropora cytherea, A. nobilis, Hydnophora rigida) in eastern Lombok Strait, Indonesia. IImuKelautan, 21: 18-27.

Baird, A.H. \& Guest, J. R. (2009). Spawning synchrony in scleractinian corals: comment on Mangubhai\& Harrison. Mar. Ecol. Prog. Ser.,374: 301-304.

Baird, A. H. \& Marshall, P. A. (2002). Mortality, growth and reproduction in scleractinian corals following bleaching on the Great Barrier Reef. Mar. Ecol. Prog. Ser., 237: 133141.

Baird, A. H.; Guest. J. R. and Willis, B. L. (2009a). Systematic and biogeographical patterns in the reproductive biology of scleractinian corals. Annu Rev EcolEvolSyst 40: 551571.

Baird, A. H.; Birrel, C. L.; Hughes, T. P.; McDonald, A.; Nojima, S.; Page, C. A; Prachett, M.S. and Yamasaki, H. (2009b). Latitudinal variation in reproductive synchrony in Acropora assemblages. Japan vs Australia. Galaxea, 11: 101-108.

Brook, G. (1892). LVI.- Preliminary descriptions of new species of Madrepora in the collection of the British Museum.- Part II. Journal of Natural History, 10 (60): 451465. 
Connell, J. H. (1978). "Diversity in tropical rain forests and coral reefs." Science 199.4335: $1302-1310$.

Dana, J. D. (1846). Zoophytes (Vol. 7). Lea and Blanchard.

Guest, J. R.; Baird, A. H.; Clifton, K. E. and Heyward, A. J. (2008). From molecules to moonbeams: spawning synchrony in coral reef organisms. Invertebrate Reproduction \& Development, 51(3): 145-149.

Guest, J. R.; Baird, A. H.; Goh. B. P. L. and Chou, L.M. (2005a). Seasonal reproduction in an equatorial reef corals. Invertebrate Reproduction and Development, 48 (1-3): 207218.

Guest, J. R.; Baird, A. H.; Goh. B. P. L. and Chou, L.M. (2005b). Reproductive seasonality in an equatorial reef corals. Coral Reefs, 24: 112-116.

Harrison, P. L.; Babcock, R. C.; Bull, G. D.; Oliver, J. K.; Wallace, C. C. and Willis, B. L. (1984). Mass spawning in tropical reef corals. Science, 223 (4641): 1186-1189.

Harrison, P. L. \& Wallace, C. C. (1990). Reproduction, dispersal and recruitment of scleractinian corals. In: Dubinsky Z (ed.) Ecosystems of the world. 25. Coral reefs. Elsevier, Amsterdam, pp: 133-207.

Hayashibara, T.; Shimoike, K.; Kimura, T.; Hosaka, S.; Heyward, A.; Harrison, P.; Kudo, K. and Omori, M. (1993). Patterns of coral spawning at Akajima Island, Okinawa, Japan. Mar. Ecol. Prog.Ser, 101: 253-262.

Hughes, T. P.; Baird, A. H.; Dinsdale, E. A.; Moltschaniwskyj, N. A.; Pratchett, M. S.; Tanner, J. E. and Willis, B.L. (2000). Supply-side ecology works both ways: the link between benthic adults, fecundity, and larval recruits. Ecology 81: 2241-2249.

Hughes, T. P.; Baird, A. H.; Bellwood, D. R.; Card, M.; Connolly, S. R.; Folke, C.; Grosberg, R.; Hoegh-Guldberg, O.; Jackson, J. B. C.; Kleypas, J.; Lough, J. M.; Marshall, P.; Nyström, M.; Palumbi, S. R.; Pandolfi, J. M.; Rosen, B. andRoughgarden, J. (2003). Climate change, human impacts, and the resilience of coral reefs. Ecology 301: 929 - 933.

Kenyon, J. C. (1995). Latitudinal differences between Palau and Yap in coral reproductive synchrony.

Kinzie, R. A. \& Buddemeier, R. W. (1996). "Reefs happen.” Global Change Biology, 2 (6): 479-494.

Levitan, D. R.; Fukami, H.; Jara, J.; Kline, D.; McGovern, T. M.; McGhee, K. E.; Swanson, C.A. and Knowlton, N. (2004). Mechanisms of reproductive isolation among sympatric broadcast-spawning corals of the Montastraea annularis species complex. Evolution, 58: 308-323.

Lough, J. M. (2008). 10th anniversary review: a changing climate for coral reefs. Journal of Environmental Monitoring, 10, 21-29.

Mangubhai, S. and Harrison, P. L. (2008a). Asynchronous coral spawning patterns on equatorial reefs in Kenya. Mar. Ecol. Prog. Ser., 360: 85-96. 
Mangubhai, S. and Harrison P. L. (2008b). Gametogenesis, spawning and fecundity of Platygyra daedalea (Scleractinia) on equatorial reefs in Kenya. Coral Reefs, 27:117122.

Mendes, J. M. and Woodley, J. D. (2002). Timing of reproduction in Montastraea annularis: Relationship to environmental variables. Mar. Ecol. Prog. Ser., 227: 241-251.

Moberg, F. and Folke, C. (1999). Ecological goods and services of coral reef ecosystems. Ecological Economics, 29: 215-233.

Oliver, J. K.; Babcock, R. C.; Harrison, P. L. and Willis, B. L. (1988). Geographic extent of mass coral spawning: clues to ultimate causal factors. In: Proceedings of 6th International Coral Reef Symposium, Townsville, 2:803-810.

Oliver, J. and Babcock, R. (1992). Aspects of the fertilization ecology of broadcast spawning corals: sperm dilution effects and in situ measurements of fertilization. The biological Bulletin, 183(3): 409-417.

Penland, L.; Kloulechad, J.; Idip, D. and van Woesik, R. (2004). Coral spawning in the western Pacific Ocean is related to solar isolation: evidence of multiple spawning events in Palau. Coral Reefs, 23: 133-140.

Randall, C. J.; Negri, A. P.; Quigley, K. M.; Foster, T.; Ricardo, G. F.; Webster, N. S. and Heyward, A. J. (2020). Sexual reproduction of Anthropocene. Mar. Ecol. Prog. Ser., 635: 203-232.

Richmond, R. H. (1997). Reproduction and recruitment in corals: critical links in the persistence of reefs. In: Birkeland C (ed) Life and death of coral reefs. Chapman \& Hall, New York, pp.: 175-197.

Richmond, R. H. and Hunter, C. L. (1990). Reproduction and recruitment of corals: Comparisons among the Caribbean, the tropical Pacific, and the Red Sea. Mar. Ecol. Prog. Ser., 60: 185-203.

Rosser, N. L. and Gilmour, J. P. (2008).New insights into patterns of coral spawning on western Australian reefs. Coral Reefs, 27:345-349.

Simpson, C. J. (1985). Mass spawning of scleractinian corals in the Dampier archipelago and the implications for management of coral reefs in Western Australia. West Aust. Dep. Conserv.Envir.Bull., 244 - 35.

Szmant, A. M. (1986). Reproductive ecology of Caribbean reef corals. Coral Reefs, 5: 43-54.

Szmant, A. M. and Gassman, N. J. (1990). The effects of prolonged bleaching on the tissue biomass and reproduction of the reef coral Montastrea annularis. Coral reefs, 8 (4): 217-224.

Tomascik, T. and Sander, F. (1987). Effects of eutrophication on reef building corals. III. Reproduction of the reef-building coral Poritesporites. Marine Biology, 94: 77- 94.

Thomas, R.S. (1962). Demonstration of structure-bound mineral constituents in thinsectioned bacterial spores by ultra-microincine Ration process. Electron microscope, 2: PR-11. 
Tooze, J. (1964). Measurement of some cellular changes during fixation of amphibian erythrocytes with osmium tetroxide solutions. Cell Biology, 22: 551-563.

Veron, J. (2000). Corals of the world, Vol. 1-3. Publisher: AIMS,Townsville, Australia.

Wallace, C.C. (1985). Reproduction, recruitment and fragmentation in nine sympatric species of the coral genus Acropora. Marine Biology, 88: 217-233.

Wallace, C.C. (1999).Staghorn Corals of The World: A Revision of The Coral Genus Acropora .CSIRO, Collingwood, CSIRO, pp.: 438.

Wijayanti, D. P.; Indrayanti, E. ;Wirasatriya, A. ; Haryanti, D. and Bhagooli, R. (2019). Reproductive seasonality of coral assemblages in the Karimunjawa Archipelago, Indonesia. Frontiers in Marine Science, 6: 195.

Willis, B. L.; Babcock, R. C.; Harrison, P. L. and Oliver, T. K. (1985). Patterns in the mass spawning of corals on the Great Barrier Reef from 1981 to 1984. Proc. 5th Int. Coral Reef, Tahiti, 4: 343-348.

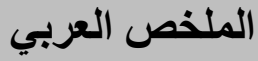

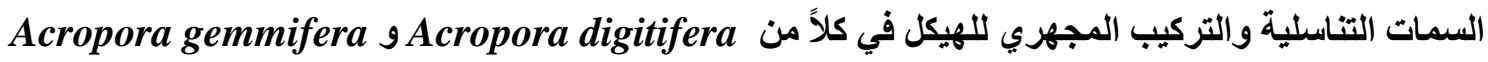
(المراجين البانية للثعاب) قاطنة شمال البحر الأحمر (الغردقة، مصر)

'محمد محمد رشاد' ، ولاء محمد شعبان"، عبدالحميد عبدالرحمن محمد علي"، هاني عبدالمجيد عبدالسلام'

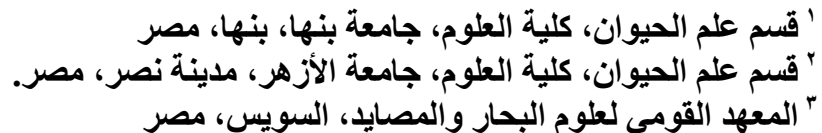

المراجين البانية للثعاب تتمو وتحافظ علي بقاء أفرادها من خلال عملية التكاثر الجنسي كأحد أهم خياراتها،

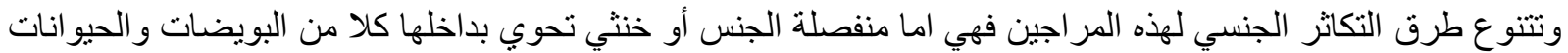

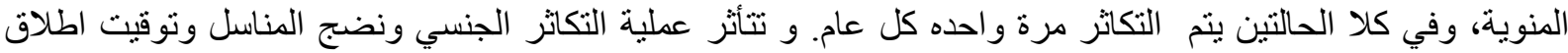

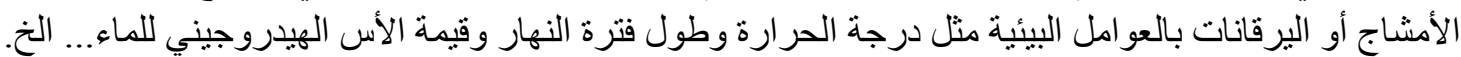

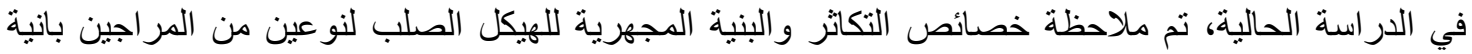

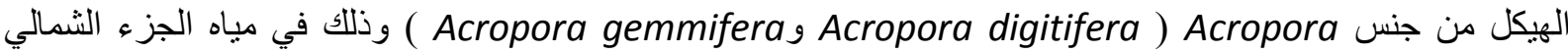

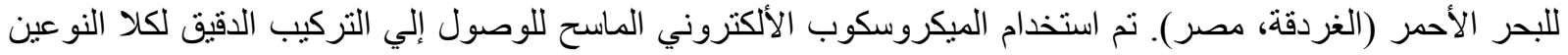

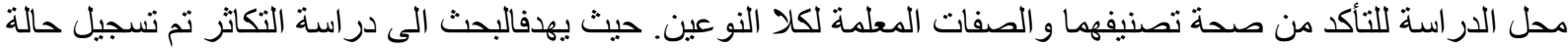

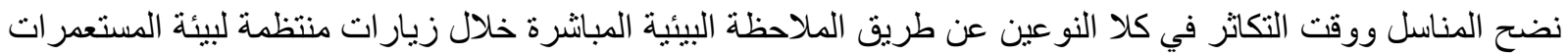

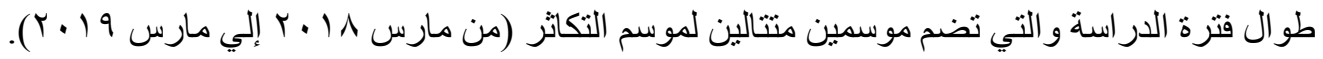

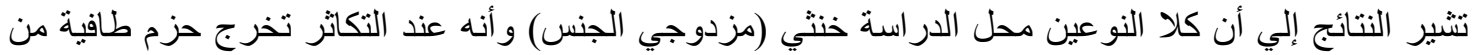

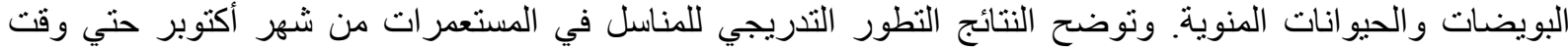



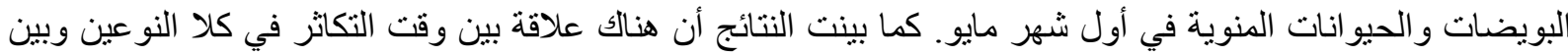

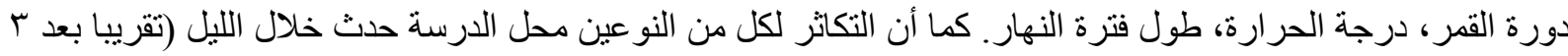

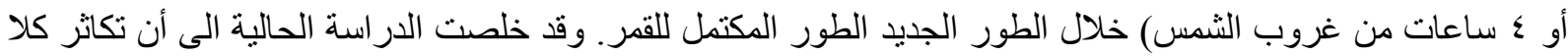
من Acropora gemmifera و Acropora digitifera يحدث قبل طور القمر المكتمل لثهر إبريل بيومين. 